Volume 16, No. 2, Juli 2019

\title{
PENGETAHUAN PENGGUNAAN ALAT PELINDUNG DIRI DI MEUBEL ALUMINIUM UD LA TAHZAN KABUPATEN HULU SUNGAI UTARA
}

\author{
Bella Amellia, Gunung Setiadi, Arifin \\ Poltekkes Kemenkes Banjarmasin Jurusan Kesehatan Lingkungan \\ Jl. H. Mistar Cokrokusumo No. 1 A Banjarbaru Kalimantan Selatan 70714 \\ E-mail: bellaamellia77@gmail.com
}

\begin{abstract}
Knowledge of the Use of Personal Protective Equipment in UD La Tahzan Aluminum Furniture in Hulu Sungai Utara Regency. The results of the preliminary survey showed that there were $50 \%$ of 10 aluminum furniture workers who knew the importance of the benefits and uses of personal protective equipment and 50\% knew less. The purpose of this study was to determine the relationship of knowledge with the use of personal protective equipment at UD La Tahzan aluminum furniture in Hulu Sungai Utara Regency. The research method used was an analytical survey with a cross sectional approach. The population in this study amounted to 35 people. Data analysis using $X^{2}$ (Chi square) test.The results of the study showed that there were 24 people who had poor knowledge there were 23 people who did not use personal protective equipment. Statistical test results ( $p=0.007)$ means that there is a relationship of knowledge with the use of personal protective equipment at UD La Tahzan aluminum furniture in Hulu Sungai Utara Regency. Suggestions for future researchers to measure lighting, noise especially the work climate because it is one of the factors that might influence the use of personal protective equipment.
\end{abstract}

Keywords: Knowledge; Personal Protective Equipment

\begin{abstract}
Abstrak: Pengetahuan Penggunaan Alat Pelindung Diri Di Meubel Aluminium UD La Tahzan Kabupaten Hulu Sungai Utara. Hasil survei pendahuluan menunjukkan pada 10 pekerja meubel aluminium terdapat 50\% mengetahui akan pentingnya manfaat dan kegunaan alat pelindung diri dan 50\% kurang mengetahui. Tujuan penelitian ini adalah untuk mengetahui hubungan pengetahuan dengan penggunaan alat pelindung diri di meubel aluminium UD La Tahzan Kabupaten Hulu Sungai Utara. Metode penelitian yang digunakan adalah survei analitik dengan pendekatan cross sectional. Populasi dalam penelitian ini berjumlah 35 orang. Analisis data menggunakan uji $X^{2}$ (Chi square). Hasil penelitian menunjukkan ada 24 orang yang memiliki pengetahuan kurang baik terdapat 23 orang yang tidak menggunakan alat pelindung diri. Hasil uji statistik $(p=0,007)$ artinya ada hubungan pengetahuan dengan penggunaan alat pelindung diri di meubel aluminium UD La Tahzan Kabupaten Hulu Sungai Utara. Saran bagi peneliti selanjutnya agar melakukan pengukuran pencahayaan, kebisingan terutama iklim kerja karena merupakan salah satu faktor yang mungkin mempengaruhi dalam penggunaan alat pelindung diri.
\end{abstract}

Kata Kunci : Pengetahuan; Alat Pelindung Diri

\section{PENDAHULUAN}

Keselamatan dan kesehatan kerja (K3) sangat penting untuk diperhatikan bagi semua tenaga kerja. Pada kenyataannya keselamatan dan kesehatan kerja juga masih sangat kurang memadai dan kurang mendapat perhatian dari instansi terkait serta masih banyak tenaga kerja yang kurang memperhatikan keselamatan dan kesehatan untuk diri sendiri dikarenakan kurangnya pengetahuan dalam menggunakan alat pelindung diri (APD) saat bekerja.

Kasus kecelakaan kerja di Indonesia menyatakan jumlah kasus kecelakaan kerja pada tahun 2015 sebanyak 110.285 kasus, tahun 2016 tercatat sebanyak 105.182 kasus, sedangkan sampai bulan agustus 2017 tercatat kecelakaan kerja sebanyak 80.392 kasus [1]. 
Salah satunya di sektor industri meubel aluminium, tentunya akan menimbulkan risiko masalah keselamatan dan kesehatan kerja bagi pekerja meubel pada tahapan proses produksi apabila tidak menggunakan alat pelindung diri saat bekerja.

Penggunaan alat pelindung diri merupakan salah satu masalah di dalam dunia kerja. Hal tersebut dapat menambah tingkat risiko kerugian baik berupa material maupun nonmaterial. Sebagai contoh, jika terjadi kecelakaan pada pekerja tentunya akan menjadi kerugian bagi pekerja [2].

Hasil survei pendahuluan melalui wawancara di meubel aluminium yang bernama UD La Tahzan di Desa Rantawan, Kabupaten Hulu Sungai Utara kebanyakan pekerja jarang menggunakan alat pelindung diri saat melakukan pekerjaan sehingga berpotensi terjadinya kecelakaan kerja ataupun penyakit akibat kerja.

Terkait tentang penggunaan alat pelindung diri dari hasil wawancara pada 10 pekerja meubel aluminium terdapat 50\% mengetahui akan pentingnya manfaat dan kegunaan alat pelindung diri dan 50\% kurang mengetahui. Berdasarkan keadaan tersebut, maka penulis tertarik melakukan penelitian untuk mengetahui hubungan pengetahuan dengan penggunaan alat pelindung diri meubel aluminium UD La Tahzan Kabupaten Hulu Sungai Utara.

\section{BAHAN DAN CARA PENELITIAN}

Metode penelitian yang digunakan adalah survei analitik dengan pendekatan cross sectional. Populasi penelitian ini adalah seluruh pekerja di meubel aluminium UD La Tahzan Kabupaten Hulu Sungai Utara yang berjumlah 35 orang pekerja. Yang menjadi variabel penelitian ini adalah variabel bebas yaitu pengetahuan. Variabel terikat penggunaan alat pelindung diri. Metode pengambilan sampel yang digunakan pada penelitian ini adalah menggunakan sampel jenuh atau sampling jenuh yaitu teknik pengumpulan sampel bila semua anggota populasi digunakan sebagai sampel [3]. Data yang diperoleh diolah secara manual, disajikan dalam bentuk tabel distribusi frekuensi. Untuk mengetahui hubungan pengetahuan dengan penggunaan alat pelindung diri di meubel aluminium UD La Tahzan Kabupaten Hulu Sungai Utara, dianalisis dengan menggunakan perhitungan statistik yaitu dengan bantuan komputer dengan uji $\mathrm{X}^{2}$ (Chi-Square). Instrumen yang digunakan dalam penelitian ini yaitu kuesioner. Kuesioner adalah sebuah daftar pertanyaan yang harus diisi oleh orang yang akan diukur (responden).

\section{HASIL PENELITIAN DAN PEMBAHASAN}

Hasil data distribusi responden pengetahuan dengan penggunaan alat pelindung diri di meubel aluminium.

Tabel 1. Pengetahuan Responden Tentang Penggunaan Alat Pelindung Diri Pekerja Meubel Aluminium

\begin{tabular}{cccc}
\hline \multirow{2}{*}{ No } & Pengetahuan & J & Jumlah \\
\hline 1. & Kurang Baik & 24 & 68,6 \\
2. & Baik & 11 & 31,4 \\
& Total & 35 & 100 \\
\hline
\end{tabular}

Berdasarkan tabel 1 diketahui bahwa responden yang memiliki pengetahuan kurang baik tentang penggunaan alat pelindung diri berjumlah 24 orang $(68,6 \%)$ sedangkan responden yang memiliki pengetahuan baik berjumlah 11 orang $(31,4 \%)$.

Hasil data distribusi responden dengan penggunaan alat pelindung diri di meubel aluminium. 
Tabel 2. Distribusi Responden Berdasarkan Penggunaan Alat Pelindung Diri Pekerja Meubel Aluminium

\begin{tabular}{cccc}
\hline \multirow{2}{*}{ No } & Alat Pelindung Diri & $\mathrm{n}$ & Jumlah \\
\cline { 3 - 3 } 1. & Tidak Menggunakan APD & 29 & 82,9 \\
2. & Menggunakan APD & 6 & 17,1 \\
& Total & 35 & 100 \\
\hline
\end{tabular}

Berdasarkan tabel 2 diketahui bahwa responden yang tidak menggunakan APD sebanyak 29 orang $(82,9 \%)$ dan menggunakan APD sebanyak 6 orang $(17,1 \%)$.

Tabel 3. Hubungan Antara Pengetahuan Dengan

Penggunaan Alat Pelindung Diri Pekerja Meubel Aluminium

\begin{tabular}{|c|c|c|c|c|c|c|c|}
\hline \multirow{3}{*}{ No. } & \multirow{3}{*}{ Pengetahuan } & \multicolumn{6}{|c|}{ Penggunaan Alat Pelindung Diri (APD) } \\
\hline & & \multicolumn{2}{|c|}{$\begin{array}{c}\text { Tidak } \\
\text { Menggunakan } \\
\text { APD }\end{array}$} & \multicolumn{2}{|c|}{$\begin{array}{c}\text { Menggunakan } \\
\text { APD }\end{array}$} & \multicolumn{2}{|c|}{ Total } \\
\hline & & $\mathrm{n}$ & $\%$ & $\mathrm{n}$ & $\%$ & $\sum$ & $\%$ \\
\hline 1. & Kurang baik & 23 & 95,8 & 1 & 4,2 & 24 & 100 \\
\hline 2. & Baik & 6 & 54,5 & 5 & 45,5 & 11 & 100 \\
\hline & Total & 29 & 82,9 & 6 & 17,1 & 35 & 100 \\
\hline
\end{tabular}

Berdasarkan tabel 3 dapat diketahui dari 24 responden yang memiliki pengetahuan kurang baik terdapat 23 orang $(95,8 \%)$ yang tidak menggunakan alat pelindung diri dan 1 orang $(4,2 \%)$ yang menggunakan alat pelindung diri. Sedangkan pada 11 responden yang memiliki pengetahuan baik terdapat 6 orang $(54,5 \%)$ yang tidak menggunakan alat pelindung diri dan 5 orang $(45,5 \%)$ yang menggunakan alat pelindung diri.

Menurut teori Budiono tahun 2003 pemilihan penggunaan alat pelindung diri harus dilakukan secara baik dan bijaksana serta disesuaikan dengan potensi bahaya yang ada, guna keefektifan alat pelindung diri yang akan digunakan oleh pekerja. Dari hasil penelitian tersebut banyaknya pekerja

yang tidak menggunakan alat pelindung diri dari 35 responden, ada 24 orang yang memiliki pengetahuan kurang baik terdapat 1 orang $(4,2 \%)$ yang menggunakan alat pelindung diri dan 23 orang $(95,8 \%)$ yang tidak menggunakan alat pelindung diri.
Dari 35 responden terdapat 11 orang pekerja $(31,4 \%)$ mengetahui seperti risiko dan bahaya dari proses produksi terutama pada proses pemotongan dan perakitan apabila tidak menggunakan alat pelindung diri dan 24 orang $(68,6 \%)$ kurang mengetahui fungsi dari penggunaan alat pelindung diri tersebut, seperti penggunaan pakaian pelindung/baju lengan panjang, kacamata, sarung tangan, masker, alat pelindung telinga dan sepatu saat bekerja. Pekerja yang memiliki pengetahuan kurang baik yang berjumlah 24 orang $(68,6 \%)$ beranggapan bahwa alat pelindung diri tersebut tidak meningkatkan keselamatan kerja tetapi menambah risiko kecelakaan kerja dan menggunakan atau tidak menggunakan itu bisa saja terjadi kecelakaan kerja, seperti penggunaan sarung tangan yang membuat potongan aluminium menempel mengakibatkan luka pada tangan dan penggunaan masker yang membatasi bernafas sehingga menimbulkan rasa panas dan sulit bernafas juga penggunaan kacamata yang mengganggu penglihatan. 
Sedangkan 11 responden yang memiliki pengetahuan baik terdapat 6 orang $(54,5 \%)$ yang tidak menggunakan alat pelindung diri dengan lengkap karena merasa kurang nyaman, dikarenakan ketidaksesuaian alat pelindung diri yang disediakan terhadap potensi bahaya pada saat bekerja dan 5 orang $(45,5 \%)$ yang menggunakan alat pelindung diri dengan lengkap. Sedangkan menurut teori bahwa pemilihan penggunaan alat pelindung diri harus dilakukan secara baik dan bijaksana serta disesuaikan dengan potensi bahaya yang ada, guna keefektifan alat pelindung diri (APD) yang akan digunakan oleh pekerja ${ }^{[4]}$.

Disimpulkan bahwa ada hubungan antara pengetahuan dengan penggunaan alat pelindung diri di meubel aluminium UD La Tahzan Kabupaten Hulu Sungai Utara. Pengetahuan yang kurang baik mempunyai risiko terhadap kecelakaan kerja pada pekerja di meubel aluminium UD La Tahzan dibandingkan dengan pengetahuan yang baik. Hasil tersebut menunjukkan bahwa pengetahuan mempengaruhi penggunaan alat pelindung diri, dengan pengetahuan yang baik maka juga diterapkan oleh pekerja dengan menggunakan alat pelindung diri saat bekerja terutama dalam proses pemotongan aluminium begitu juga sebaliknya. Pada pekerja yang memiliki pengetahuan baik, ada juga memiliki praktek yang kurang baik dalam hal penggunaan alat pelindung diri. Hal ini dapat disebabkan karena mereka belum memiliki sikap yang baik terhadap alat pelindung diri. Ini didukung dengan pengalaman pribadi yang selama ini tidak menggunakan alat pelindung diri namun tidak mengalami gangguan kesehatan.

Hal ini juga selaras dengan teori, Lawrence Green menganalisa bahwa faktor perilaku sendiri ditentukan oleh 3 faktor utama salah satunya disposing factors atau faktor predisposisi yaitu faktor-faktor yang memudahkan atau mempredisposisi terjadinya perilaku seseorang, faktor ini mencakup diantaranya pengetahuan [5].

Sesuai teori maka hal ini responden belum mencapai tahap adoption dalam perubahan perilaku yaitu berperilaku baru sesuai dengan pengetahuan, kesadaran, dan sikapnya terhadap stimulus [5].

Pengetahuan subyek diperoleh dari hasil peinderaan mempunyai 6 tingkatan yaitu tahu (know), memahami (comprehension), aplikasi (application), analisis (analysis), sintesis (synthesis) dan evaluasi (evaluation)[6].

\section{KESIMPULAN DAN SARAN}

Pada meubel aluminium UD La Tahzan Kabupaten Hulu Sungai Utara pekerja lebih banyak memiliki pengetahuan kurang baik berjumlah 24 orang $(68,6 \%)$ dan pengetahuan baik berjumlah 11 orang $(31,4 \%)$. Sedangkan sebanyak 29 orang $(82,9 \%)$ tidak menggunakan alat pelindung diri dan 6 orang $(17,1 \%)$ yang menggunakan alat pelindung diri. Artinya ada hubungan antara pengetahuan dengan penggunaan alat pelindung diri di meubel aluminium UD La Tahzan Kabupaten Hulu Sungai Utara. Untuk saran bagi peneliti selanjutnya agar melakukan pengukuran pencahayaan, kebisingan terutama iklim kerja karena merupakan salah satu faktor yang mungkin mempengaruhi dalam penggunaan alat pelindung diri.

\section{KEPUSTAKAAN}

1. Badan Penyelenggara Jaminan Kesehatan. Kasus Kecelakaan Kerja Di Indonesia. 2018;

2. Panggabean R. Hubungan Pengetahuan dan Sikap Petugas Labolatorium terhadap Kepatuhan SOP di Puskesmas Pekan Baru. Medan: Sekolah Pasca Sarjana. Universitas Sumatera Utara.Tesis; 2008.

3. Sugiyono. Metode Penelitian Kuantitatif Kualitatif dan R\&D. Bandung: Alfabeta; 2006.

4. Budiono S. Bunga Rampai Hiperkes dan Keselamatan Kerja. Semarang: Badan Penerbit Universitas Diponegoro; 2003.

5. Notoatmodjo S. Ilmu Kesehatan Masyarakat Prinsip-Prinsip Dasar. Rineka Cipta.; 2003.

6. Triwibowo C, Pusphandani M. Kesehatan Lingkungan dan K3. Yogyakarta: Nuha Medika; 2013. 